\title{
Comaprison of Iron Nanowires Fabricated via Porous Anodic Aluminium Oxide Template by a.c and d.c. Electrodeposition
}

\author{
*Prabhjot Kaur ${ }^{1}$, Sangeeta Sharma ${ }^{2}$, M.K Kushwaha ${ }^{3}$ \\ ${ }^{1}$ Research Scholar, I.K.Gujral Punjab Technical University, Kapurthala \\ ${ }^{2}$ Associate Professor, Department of Applied Sciences and Humanities, Shaheed Bhagat Singh State Technical \\ Campus, \\ ${ }^{3}$ Associate Professor, Department of Mechanical Engineering, Shaheed Bhagat Singh State Technical Campus, \\ Ferozepur (Punjab)-152004, India Author for correspondence
}

\begin{abstract}
In present study nanowires of iron were fabricated by both alternate current (a.c) and direct current (d.c) by using nanoporous anodized aluminium as a template. Nanowires in anodic alumina template were fabricated by electrodeposition method. It has been investigated that synthesis of nanowires is possible by using both a.c and d.c electrodeposition. The nanowires obtained by using a.c electrodeposition were elongated and more stable where as nanowires fabricated by using d.c electrodeposition were less stable. Optimum time attained for the synthesis of nanowires in a.c depostion was 5 minutes where as in case of d.c deposition nanocrystals of different shapes were obtained due to less stability. Average diameter of nanopores obtained in anodized aluminium was $150 \mathrm{~nm}$ by using phosphoric acid as a electrolyte. Length of nanowires obtained by using a.c and d.c electrodeposition was $683 \mathrm{~nm}$ and $640 \mathrm{~nm}$ respectively.
\end{abstract}

\section{Introduction}

During recent years, nanowires becomes an apple of eye for research era because of their potential applications in diverse fields such as nanoelectronics, opto-electronics, semiconductors, sensors and in the formation of biomolecules [1,3]. Many studies have focused on the fabrication of nanowires [4-6] via anodic aluminium oxide (AAO) template for their potential applications in the micro/nanoelectronics industry and environmental applications. Many methods have been developed for the fabrication of metallic nanowires but via template synthesis is considered to be most suitable and useful for growth of nanowires. Electrochemical deposition route is easy, low-cost as well as less cumbersome compared to other fabrication techniques, namely, pulsed laser deposition (PLD), vapour-liquid-solid (VLS) method and chemical vapour deposition (CVD) [710]. In present work nanowires by using a.c as well as d.c electrodeposition were fabricated via AAO. Morphology of electrodeposited iron nanowires has been studied using field emission scanning electron microscopy (FE-SEM) with energy dispersive X-ray spectroscopy (EDX). Anodic alumina layer of $150 \mathrm{~nm}$ pore diameter were synthesized before the fabrication of nanowires.

\subsection{Anodization}

\section{Experimental}

Aluminum specimens were cut from 99.99\% pure sheet having thickness of $0.7 \mathrm{~mm}$ into square shaped having an area of $1 \mathrm{~cm} \times 1 \mathrm{~cm}$. After cutting, samples were first degreased in ethanol for $200 \mathrm{~s}$, then washed in deionized water and air-dried for $12 \mathrm{hrs}$. Anodization was carried out on these samples by using $0.3 \mathrm{M}$ orthophosphoric acid at constant temperature $35{ }^{\circ} \mathrm{C}$ with varying potential range from $140 \mathrm{~V}$ to $170 \mathrm{~V}$. Before anodization electropolishing was performed as a pre-treatment to smoothen the surface. The average surface roughness factor (Ra) was measured with the help of Surfest SJ-210, MITUTOYO portable surface roughness tester. Morphology of nanoporous anodized aluminium was determined by ZEISS FE-SEM associated with EDX. After one step anodization, it is necessary to perform thinning of barrier layer to get more ordered pores. For thinning of barrier layer $100 \mathrm{ml}$ of solution was made by mixing $1.8 \%$ of $\mathrm{CrO}_{3}\left(1.8 \mathrm{~g}+6 \mathrm{ml} \mathrm{H}_{3} \mathrm{PO}_{4}\right.$ in $100 \mathrm{ml}$ of $\mathrm{H}_{2} \mathrm{O}$ ) and $6 \%$ of $\mathrm{H}_{3} \mathrm{PO}_{4}$. Then solution was heated upto $70{ }^{\circ} \mathrm{C}$ for $1 \mathrm{hr}$ by dipping aluminium stripes which were anodized in previous step. After thinning of barrier layer dried the samples and again anodized as in one step. After two step anodization the samples were dipped into $3 \mathrm{wt} \%$ orthophosphoric acid solution for $20 \mathrm{~min}$ to widen pores.

\subsection{Fabrication of Nanowires}

For deposition took mixture of $\mathrm{FeSO}_{4}(20 \mathrm{~g})$, Ascorbic acid (0.5g), Boric acid (3g) and made $500 \mathrm{ml}$ solution. Then electrodeposition was done by dipping two samples in above prepared solution simultaneously at a.c voltage of $15 \mathrm{~V}$ for $2-5$ minutes. In d.c electrodeposition pure aluminium sample was used as anode and anodized aluminium was used as a cathode in the same solution for $2-5$ minutes. 


\section{Results And Discussion}

Experiments were carried out at all the parameters detailed above and it has been investigated that the best ordered nanoporous oxide film was obtained when anodization was carried out by using $0.3 \mathrm{M} \mathrm{H}_{3} \mathrm{PO}_{4}$ at $150 \mathrm{~V}$ having temperature range $30 \pm 5^{\circ} \mathrm{C}$ for $1 \mathrm{hr}$. FE-SEM image at these parameters is shown in figure 1.
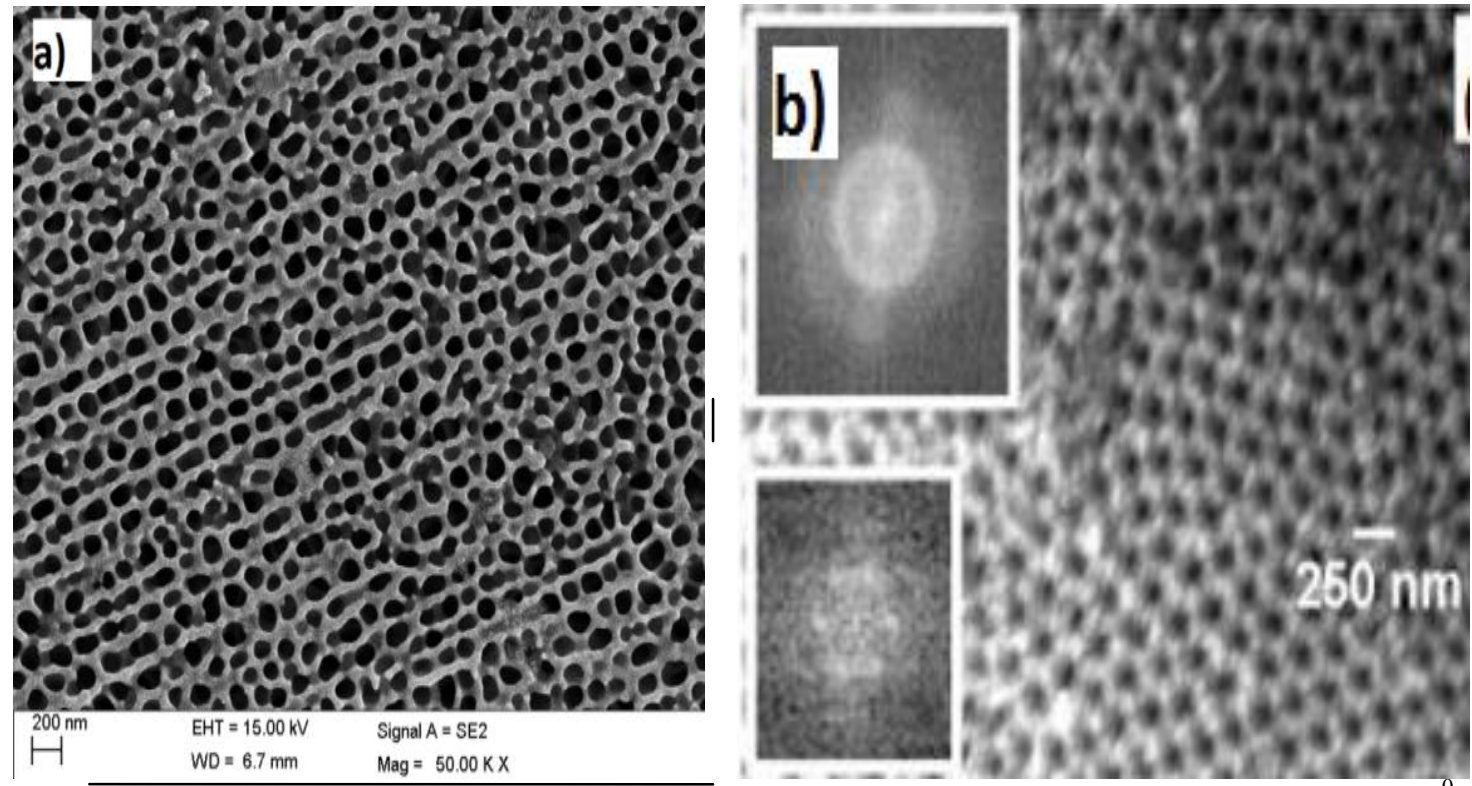

Figure 1. FE-SEM top view micrographs for anodized samples at $150 \mathrm{~V}$ in $0.3 \mathrm{M} \mathrm{H}_{3} \mathrm{PO}_{4}$ for $1 \mathrm{hr}$ at $30 \pm 5^{\circ} \mathrm{C}$ at a scale of a) $200 \mathrm{~nm}$ b) $250 \mathrm{~nm}$ with FFT showing regularity of pores.

As seen in figure 2, the morphology of iron nanowires obtained of rod shaped having length of $683 \mathrm{~nm}$ and having diameter of $103.0 \mathrm{~nm}$ by using a.c electrodepostion. Confirmation of iron nanowires was done by EDX compiled with FE-SEM as shown in figure 3.
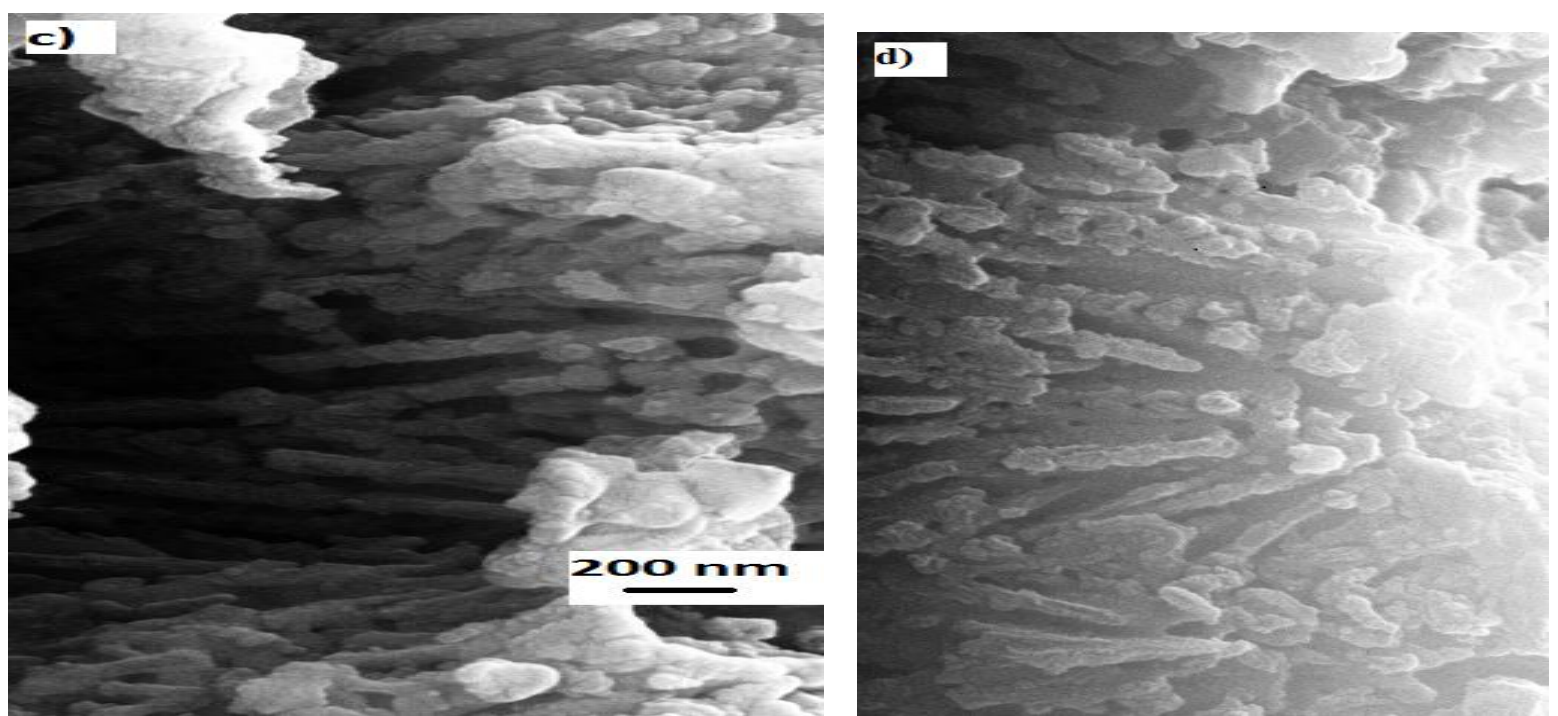

Figure 2. FE-SEM cross-sectional view micrographs of nanowires anodized at $150 \mathrm{~V}$ in $0.3 \mathrm{M} \mathrm{H}_{3} \mathrm{PO}_{4}$ for $1 \mathrm{hr}$ at $30{ }^{\circ} \mathrm{C}$ Iron Nanowires at ac electrodeposition at a scale of $200 \mathrm{~nm}$

Nanowires formed at d.c electrodeposition are shown in figure 3 having length of $643 \mathrm{~nm}$. At d.c electrodeposition there is formation of nanoclusters after 5 minutes as shown in figure 3 (b). 

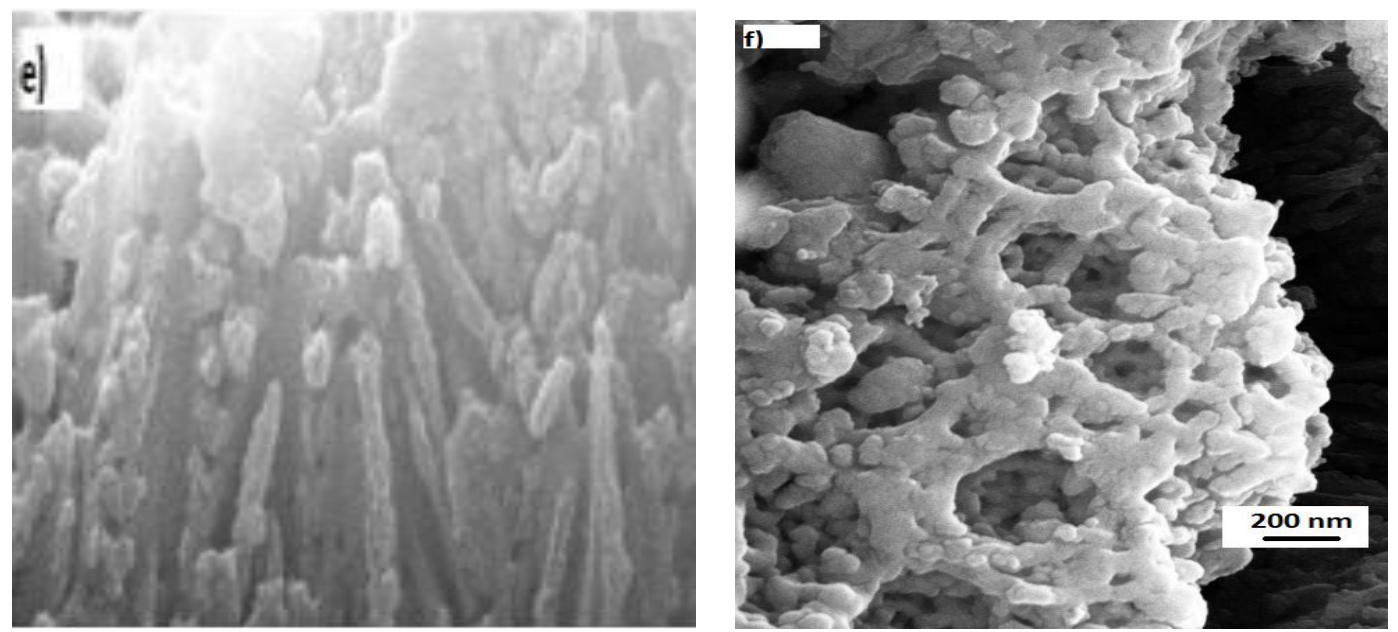

Figure 3. FE-SEM cross-sectional view micrographs of nanowires anodized at $150 \mathrm{~V}$ in $0.3 \mathrm{M} \mathrm{H}_{3} \mathrm{PO}_{4}$ for $1 \mathrm{hr}$ at $30{ }^{\circ} \mathrm{C}$ e) Iron Nanowires at dc electrodeposition f) nanoclusters after 5 minutes at a scale of $200 \mathrm{~nm}$.

The reason of formation of nanoclusters at d.c electrodeposition is less stability of nanowires which gets distorted with increase in time whereas nanowires obtained by a.c deposition remain stable after 5 minutes.

\section{Conclusion}

The present study investigated that the nanowires can be formed by a.c as well as d.c electrodeposition via anodic aluminium oxide template. Nanowires fabricated by a.c deposition were more stable and elongated as compared to d.c. electrodeposition. Optimum time attained for the fabrication of nanowires was found to be 5 minutes.

\section{Acknowledgments}

The first author Prabhjot Kaur, being a Research Scholar of I.K. Gujral Punjab Technical University, Kapurthala highly acknowledge this university for its valuable inputs on presented research. Furthermore, authors appreciatively acknowledge I.I.T. Roorkee and Director Dr. T.S. Sidhu, Shaheed Bhagat Singh State Technical Campus, Ferozepur for their support in building up experimental setup and characterization respectively.

\section{References}

[1]. Masuda, H., Fukuda, K., (1995), "Ordered Metal Nanohole Arrays Made by a Two-step Replication of Honeycomb Structures of Anodic Alumina",Science, 268, pp. 1466

[2]. Masuda, H., Hasegwa, F., (1997), "Self-ordering of Cell Arrangement of Anodic Porous Alumina Formed in Sulfuric Acid Solution", Journal of Electrochemical Society, 144(5), pp. 128.

[3]. Landolt, D., (1987), “Fundamentals Aspects of Electropolishing”, Electrochimica Acta, 32(1), pp. 1-11.

[4]. Lee, P.J., (1996), "Enhanced Control of Electropolishing for Preparation of Thin Foils for Transmission Electron Microscopy: Artificial and Multiple Phase Micro- Electropolishing”, Proc. Microscopy \& Microanalysis, Minneapolis, pp.1028-1029.

[5]. Peighambardoust, N-S., Nasirpouri, F., (2013), "Electropolishing Behaviour of Pure Titanium in Perchloric Acid- MethanolEthylene Glycol Mixed Solution”, The International Journal of Surface Engineering and Coatings, 92(3), pp. 132-139.

[6]. Kaur, H., Sharma, L., Kaur, P., Sharma, S., Kushwaha, M., (2013), "An Alternative Treatment to Electropolishing: Chemical Polishing", Journal of Advances in Chemistry, 1(1), pp.1-4.

[7]. Kushwaha, M., Kaur, H., Thareja, P., (2011), "Effect of Anodization Process Parameters on Morphology of Porous Anodic AluminumOxide and Carbon Nanotubes Grown by CVD", Journal of Production Research \& Management, 1(3), pp. 1-16.

[8]. Lai, M.; Riley, D.J.; J. Colloid interface sci., 2008, “Templated electro synthesis of nanomaterials and porous structures,” 323, 203.

[9]. Cui, Y.; Wei, Q.; Park, H.; and Lieber, C.; Science, 2001b, "Nanowire Nanosensors for Highly Sensitive and Selective Detection of Biological and Chemical Species", 293, 1289.

[10]. Kertopu, G.; and Yalein, O.; University of Norttinggham, Nigde, U.K. Turkey., 2010, "Fabrication and applications of metal nanowire arrays electrodeposited in ordered porous templates," 228.

IOSR Journal of Applied Chemistry (IOSR-JAC) is UGC approved Journal with Sl. No. 4031, Journal no. 44190 .

Prabhjot Kaur. "Comaprison of Iron Nanowires Fabricated via Porous Anodic Aluminium Oxide

Template by a.c and d.c. Electrodeposition." IOSR Journal of Applied Chemistry (IOSR-JAC) 10.7

(2017): 18-20 